\title{
Factors influencing career choice: the Romanian business and administration students' experience
}

\author{
assoc. prof. Laura Elena MARINAS ${ }^{1}$, PhD \\ univ. lecturer Ramona Stefania IGRET ${ }^{1}$, PhD \\ assoc. prof. Cristian Virgil MARINAS ${ }^{1}, \mathrm{PhD}$ \\ Eugen PRIOTEASA ${ }^{1}$, PhD Student
}

\begin{abstract}
The paper aims to identify and rank the factors influencing Romanian business and administration students' career choice. The main assumptions refer to: (a) good university education is critical factors influencing career choice; (b) business and administration students' career choices are influenced by extrinsic factors; (c) students' early exposure to profession contribute to successful careers. The paper findings are based on data collected from 496 undergraduate and master programs students enrolled in business and administration university education programs at Bucharest University of Economic Studies (BUES) during 2014/2015 academic year. BUES undergraduate and graduate students were distributed a questionnaire with 17 questions. Crosstabulation, frequency analysis and descriptive statistics were used for processing data collected. The survey conducted had broader objectives; therefore, there will be presented only results obtained after processing some of the questions of the survey which considered relevant for the aim of this paper. The findings indicate that extrinsic and interpersonal factors are significantly influencing career choice of business and administration students. Results are relevant for the university management: successful integration of graduates is becoming part of the quality assurance for any university. Accurate knowledge about factors influencing students' career choice is needed to university staff so that to design and implement tools to support students to make the "right" career choice and to contribute to sustainable insertion of its graduates to the labor market. Thus, university staff has to identify perceptions and factors influencing students' career choice so that to design and implement tools to support students' career development.
\end{abstract}

\section{Factors influencing students' career choices}

Career choice implies students' or recent graduates' decision of selecting the occupation and professional field which fit best to their individual needs (Gokuladas, V.K., 2010). Apart of the competencies and skills self-assessment and the evaluation of career alternatives, the decision made refers to the field of activity and the employer profile to work for and is dependent to the individual preferences over alternative career options.

According to Carpenter and Foster (1977) and Beyon et al. (1998), the career choice is dependent of three categories of factors: extrinsic, intrinsic and interpersonal. Extrinsic factors are not inherent in the nature of the tasks or of the occupational role (Willis, S.C et al, 2009) and may include labour market conditions (Edvardsson Stiwne, E. 2005), employer brand, salaries and income, job security (Gokuladas, 2010, Aycan et Fikret- 
Pasa), job availability, good remuneration and/or prestige of the occupation/job (Carpenter et Foster, 1977; Beyon et al, 1998). Intrinsic factors focus on the job content and the opportunities it provides for further training, career and professional development. The intrinsic factors include specific job related factors, such as authority and power related to the job (Bai, 1998; Aycan et Fikret-Pasa, 2003), working conditions and professional and career advancement opportunities (Aycan et Fikret-Pasa, 2003, Gokuladas 2010), creativity and professional challenges incurred (Feton S et al, 1994), interest for a specific job, content of the work and satisfaction (Carpenter et Foster, 1977; Beyon et al, 1998), training and professional development opportunities (Gokuladas, V.K., 2010). Interpersonal factors may include parental, family, relatives and/or friends and/or professors' influence (Carpenter et Foster, 1977; Beyon et al, 1998, Gokuladas, 2010), early exposure to profession (Willis, S.C., 2009).

Willis et al (2009) concluded that career choice decision is the result of a combination of factors and values located in personal experience. Willis et al (2009) regrouped these factors and values under 4 categories: personal identity (gender, ethnicity), social (family, professional status, career myths), instrumental (financial security, job security, flexibility, autonomy, vocational training) and personal experience related factors.

Students' ranking of factors influencing their career choice may differ across cultures $(\mathrm{Ng}$ et al, 1998), field of studies and industry (Gokuladas, V.K., 2010). Agricultural economics students' career choice (McGraw, K., 2012) across industries is influenced by previous professional experience, sector preference, career goals, skills and experience and job attributes (combination of intrinsic factors related to job responsibility and career advancement opportunities and extrinsic factors related to salaries). Indian engineering students first career choice (Gokuladas, 2010) is mostly influenced by intrinsic factors (in particular, training, professional development and career opportunities in engineering available within company, working conditions), while extrinsic factors (such as company brand, job security and remuneration) were less relevant; students from rural area are more influenced by extrinsic and interpersonal factors as compared to urban students for whom intrinsic factors are clearly prevailing. Differences were observed across study fields in engineering: computer sciences and IT branch students were more influenced by intrinsic or extrinsic factors when choosing a career in ICT field, unlike non computer science and IT students for whom an ICT career choice is rather dependent on interpersonal factors (Gokuladas, 2010). UK pharmacy students' career choice is influenced by a combination of intrinsic and extrinsic factors (Willis et al, 2009), most relevant motivators for their choice covering opportunities to earn a high income and favorable employment prospects, the content and nature of the pharmacy work, professional status, working conditions, flexibility (Willis et al, 2009; Gleeson et al, 1993); available studies also identifies early exposure to pharmacy work as factor influencing the choice of a pharmacy career (Willis et a, 2009), in particular, previous personal contacts with a pharmacist (Carlson and Wertheimer, 1992; Rascati, 1989), as an important interpersonal factors. According to Willis et al (2009), students are more likely to justify their career choice in terms of a rational economic model of participation to higher education, rather than in relation to the nature of pharmacy work; these findings indicate that students' option for pharmacy university studies defines their career choice for pharmacy or related fields. According to Felton et al (1994), the US business students' 
option for a career in accounting is less influenced by intrinsic factors (such as creativity, intellectual challenge and autonomy in task completion) than their option for a nonaccounting career, but rather by extrinsic factors related to long term earnings and job market opportunities. Felton et al (1994) indicates that business students opting for nonaccounting career are rather concerned with intrinsic factors and good initial earnings as extrinsic factor.

According to Greenbank (2011), students' option for university education in a specific study area is dependent of the aim of enhanced employability; thus, the educational choice, in particular related to the study area, is determining students' preferences for future career paths ( $\mathrm{Ng}$ et al, 2008; Kopanidis et Shaw, 2014). University learning paths and specialization are shaping the student career pathways (Da Silva Anana and Nique, 2010). University education in engineering, science, technology and business are rather employability oriented and are equipping students with practical skills and job related competencies (Goyettet et al, 2006; Kopanidis et Shaw, 2014), while university education in arts, humanities and social sciences are tending to foster learning for its own sake (Bennett, 2004). A survey conducted on Australian students enrolled in three main areas (business; art, design and social context; sciences and engineering technologies) indicated that students are selecting university study programs based on their values which are associated with various specific career pathways (Kopanidis et Shaw, 2014). Thus, the prospective university students' option for particular educational paths or field of study is the result of a matching process of their personal interest and career objectives (Kopanidis et Shaw, 2014); the option for a particular field of university studies should be considered an early predictor of students' career preferences, in particular in vocational and professional fields, such as pharmacy, medicine, accounting, health etc. (Kopanidis et Shaw, 2014; Willis et al 2009).

Based on a cost-benefit approach applied on business, education and psychology students, Wheeler (1983) concluded that the individuals' perception about the reward (benefits) - costs ratio of an occupation/profession is more a determinant of career choice than benefits or costs assessed independently. This confirms later findings that career choice, is normally influenced by objective factors as well as subjective factors which may be regrouped under the category of perceptions (Gokuladas V.K., 2010) about various professions and careers. Students' perceptions when making their first career choice depend on: (a) the specific information they have from various sources, including, family, friends, career counsellor, media (Julien, 1999), employers (Gokuladas, V.K., 2010) about labour market conditions (Bai, 1998), occupations and professions and (b) the attitudes and beliefs they have developed about career opportunities during their life (Gokuladas, V.K., 2010) based on personal treatment of specific information acquired.

\section{Paper aims and methodology}

The paper aims to identify and rank the factors influencing Romanian business and administration (BA) students' career choice. The main assumptions refer to: (a) good university education is critical factors influencing career choice; (b) business and 
administration students' career choices are influenced by extrinsic factors; (c) students' early exposure to profession contribute to successful careers.

The paper findings are based on data collected from undergraduate and master programs students enrolled in business and administration (BA) university education programs at Bucharest University of Economic Studies (BUES) during 2014/2015 academic year. With more than 100 years of tradition and over 300.000 Alumni, BUES is one of the most prestigious universities in the economics, business and administration in Romania. BUES has 12 faculties offering the opportunity to study in different languages (Romanian, English, German, French) for over 21,000 students who may choose over 22 Bachelor's Programs, 88 Master Programs, 10 research areas for PhD studies and 130 programs for postgraduate studies (Nastase, P., 2016). This is the reason for which we have considered BUES the most representative university for business and administration education in Romania and decided to conduct the survey at this university. The survey conducted had broader objectives; therefore, there will be presented only results obtained after processing some of the questions of the survey which considered relevant for the aim of this paper.

Data were collected from $496 \mathrm{BA}$ undergraduate and master students though a questionnaire with 17 questions. The questionnaire is based on he tri-dimensional model of extrinsic, intrinsic and interpersonal factors developed by Carpenter and Foster (1977) and Beyon et al. (1998); similar studies on career choice (Willis et al, 2009; Kopanidis et Shaw, 2014) were also considered. Before the survey, a focus group (HR practitioners, academics, students and stakeholders in education) was organized to improve the questionnaire. A draft version of the questionnaire was tested during a pilot phase on 30 persons in October 2014 before the final version of the questionnaire was developed. Except of the questions related to the profile of the respondents (Q1-Q6), the questionnaire contains multiple choice questions, open ended text questions and matrix table questions (Q7-Q17). The questionnaire is structured on five parts. The first part refers to the profile of the respondent (Q1-Q4), while the second part (Q5-Q6) is assessing the working experience (duration and type) of the respondents. The working experience referred to experience related to volunteering, employment in public or private organization, internship experience or no experience. It was aimed at identifying if and at what extent, the personal exposure to the profession (early working experience) of BA students, regardless the type of exposure, is affecting the students' perception about career opportunities (Gokuladas, 2010) and their career choice (Willis, 2009). The third part (Q7) attempts to identify and rank the main factors influencing the career choice of the Romanian BA students. Students were asked (Q7) to rank to a 6 point Likert scale (1 - least important, 6- most important) the factors influencing their career choice; factors were depicted as follows: family/parental, faculty/university, friends, colleagues and professors, economic and social climate, other factors (to be indicated by the respondent). The fourth part (Q8-Q9) aimed to identify the prospective career paths by asking BA students to identify and rank sectors and type of employers they prefer. The fifth part (Q10-Q17) was designed to identify motivators influencing career choice of BA students. It is developed according to the tri-dimensional model of extrinsic, intrinsic and interpersonal factors, (Q10-Q12); also future career path and job motivation factors were identified and ranked (Q13-Q17). Q10 asked students to indicate the 3 most 
important factors for a successful career; the items of Q10 were depicted as follows: family educational status, family financial status, good education, hard work, native skills (talent, IQ), good networking, ambition, luck, obedience, good personal branding skills, good foreign language communication skills, adaptability, others (to be indicated by the respondent). Q11 was aimed to rank the influence that various types of working experiences may have on career choice by using a 4 points Likert scale (4 - very high influence, 1 - very low influence); the working experience was depicted by the following items: internships, volunteering, entrepreneurship, paid work (various types of employment). Q12 asked students to rank the three most important factors for their career choice. Q13 - Q17 contained items allowing identification and ranking of relevant factors influencing students' satisfaction at work. The questionnaire (printed version) was distributed, during October 2014 - May 2015, to 1200 BUES' undergraduate and master students enrolled in the at 11 faculties: Business Administration; Public Administration and Management; Business and Tourism; Cybernetics, Statistics and Economic Informatics; Accounting; Theoretical and Applied Economics; Agricultural and Environmental Economics; Finance, Insurance, Banking and Stock Exchange; Management; Marketing; International Business and Economics. There were 496 valid questionnaires which were processed which leads to a rate of response of $41.33 \%$. Crosstabulation, frequency analysis and descriptive statistics were used for processing the data collected.

The respondents profile was outlined by means of frequency analysis and is depicted in Table 1.

Table 1. Demographic profile

\begin{tabular}{ll}
\hline Gender & Percentage (\%) \\
\hline Male & $18.35 \%$ \\
\hline Female & $81.65 \%$ \\
\hline Age distribution & \\
\hline Under 20 & $23.19 \%$ \\
\hline $21-25$ & $73.39 \%$ \\
\hline $26-30$ & $2.83 \%$ \\
\hline $31-40$ & $0.41 \%$ \\
\hline $41-50$ & $0.20 \%$ \\
\hline Study level & \\
\hline Bachelor & $78.63 \%$ \\
\hline Professional and Research Master & $21.37 \%$ \\
\hline Residence & \\
\hline Urban, large cities & $58.67 \%$ \\
\hline Urban, medium and small cities & $21.77 \%$ \\
\hline Rural & $19.45 \%$ \\
\hline Employment status & \\
\hline No employment contract & $47.78 \%$ \\
\hline Less than 1 year & $33.06 \%$ \\
\hline $1-5$ years & $16.13 \%$ \\
\hline 6-10 years & $2.02 \%$ \\
\hline 11-20 years & $0.81 \%$ \\
\hline Over 20 years & $0.20 \%$ \\
\hline Type of working experience & \\
\hline Volunteer (in NGOs) & $21.98 \%$ \\
\hline
\end{tabular}




\begin{tabular}{ll}
\hline Employee in a public institution & $3.23 \%$ \\
\hline Employee in a private company & $24.60 \%$ \\
\hline Internship & $16.73 \%$ \\
\hline Entrepreneur or former entrepreneur & $1.61 \%$ \\
\hline No relevant working experience & $31.85 \%$ \\
\hline
\end{tabular}

As shown in table 1 above, most of the respondents are under 25 years old $(96.58 \%)$ and enrolled in undergraduate studies $(78.36 \%)$. Data cross-tabulation indicates that: (a) most bachelor students are recent high school graduates and (b) bachelor graduates are completing their education by enrolling in master and other graduate programs since university education remain a relevant factor for successful careers ensuring access to better paid jobs (UNICEF, 2014)

The respondents profile by working experience may be considered an early predictor about the importance of interpersonal factors, namely the exposure to profession, for students' career choices. It also reflects the BA students' perceptions that previous working experience (assuring early exposure to profession) remains important for their employability and further career choice: internships (38.71\%), employment contracts $(27.83 \%)$ and volunteering $(21.98 \%)$ are main tools to increase employability. The respondents profile by employment status is also reflecting the students' perceptions: most students are not employed in early stages of their university education programs, but they are looking for employment starting with the $2^{\text {nd }} y$ ear of bachelor, in particular in private companies (public institutions are more closed to employ unexperienced persons and have more rigid working hours approach), not only to finance their studies, but also for future employability reasons as indicated above.

\section{Main results and discussions}

The Q7 asked students to rank on 6 points Likert scale (1 - least important, 2 less important, 3 - relatively important, 4 - important, 5 - very important, 6 - most important). Based on the answers given by the 496 respondents at the Q7, the three most important factors influencing the BA students' career choice, ranked according to the mean scores, are the university or faculty graduated, family and social and economic climate (table 2).

Table 2. Mean and standard deviation of the factors influencing career choice - Q7 (

\begin{tabular}{|l|l|l|l|l|l|}
\hline & Family & Faculty/university Friends & Colleagues/professors Economic and \\
social climate
\end{tabular}

Based on the mean scores, the factors most influencing BA students' career choice are: the university/faculty graduated, economic and social climate and family, while friends and professors advice are considered less important. Based on the frequency analysis, family was ranked among three most important factors influencing career choice by over $60 \%$ of the BA students, while the university/faculty graduated and the economic and social climate were ranked among three most important factors by $76 \%$ and $62 \%$ of the 
respondents respectively. The results of the survey confirms that for Romanian BA students' educational route, respectively their option for a certain university and a specific field of study, is an early predictor of their career choice and development, confirming thus the results of previous research of Kopanidis and Shaw (2014), Willis( 2009) and Greenbank (2011). The emphasis of university/faculty as a determinant of career choice is important to be analyzed. On the one hand, it seems to indicate that initial career choice is made after secondary education when opting for a particular university and field of study. It indicates that guiding and counselling during upper secondary education becomes an important tool to shaping students' future professional paths and it should be improved to accompany students throughout their high school life. On the other hand, since family is the third most important factor influencing career choice, it becomes crucial that all guiding and counselling activities during secondary education should target also students' families for better results.

The Q8 asked students to rank the economic sectors they are considering for their career development. It was used a 4 points Likert scale (1 - preferred, 2 - possible, 3 - unlikely, 4 - excluded). For each sector, students were asked to indicate their preference on scale from 1 to 4. Students were indicated 13 sectors to consider and rank (agriculture; manufacturing; public administration; retail and wholesale trade; transportation; tourism; mass media; cultural activities; ICT; finance banking and insurance; education and research; health and social work; sport management) and had the possibility to indicate another economic sector. Findings indicate that the most attractive sectors are: finance banking and insurance, retail and wholesale trade and public administration. The least attractive sectors for BA students' career were agriculture, sport management, health and social work, transportation (chart 1).

Chart 1. Students' preference for economic sectors - Q8

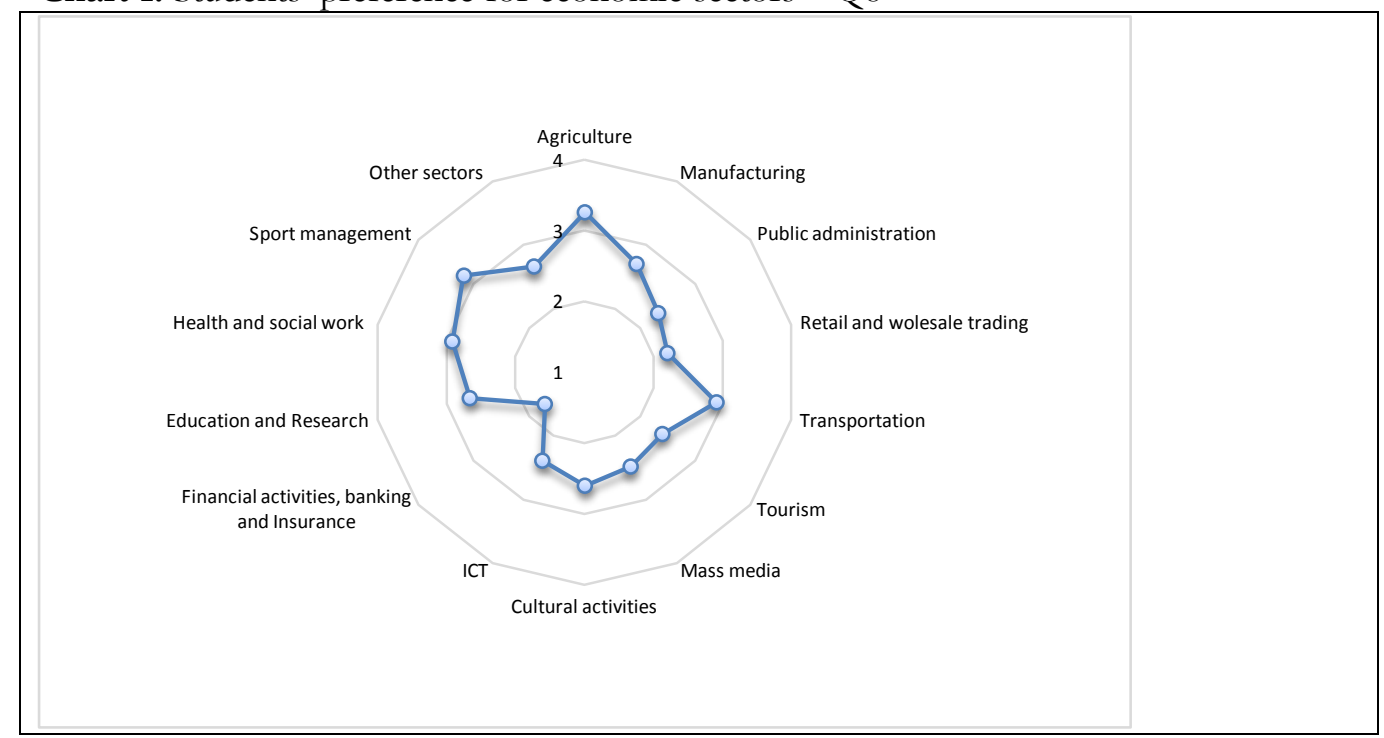

If the importance given to the economic climate (ranked as the $2^{\text {nd }}$ most important) and results obtained at Q8 are combined, it seems that extrinsic factors are critical for BA 
students' career choice. Economic and social climate reflected in labor market conditions (Edvardsson Stiwne, E. 2005), earnings and job availability (Beyon et al, 1998; Carpenter et Foster, 1977) is underpinning students' option for financial activities, banking and insurance; preference for financial activities, banking and insurance is to be justified since most vacancies in this sector are requiring economic studies. Also, perception about good salaries and good employer brand (Gokuladas, 2010) associated to financial and banking sector (also supported by statistical data) is still widespread across nowadays generation of BA students despite recent financial and banking turbulences in Europe. Similarly, traditional perception about hardworking conditions and negative employer brand in agriculture (Gokuladas, 2010, McGraw, K., 2012) and students' perception of limited use of modern management tools in agriculture, arts, and sport impacting on limited job availability (Carpenter et Foster, 1977; Beyon et al, 1998) for economic university education graduates ranked agriculture and sport management among the least preferred sectors for their future career development. Health sector and social work are considered highly specialized (Willis, 2009), requiring medical, psychology and social sciences education which is explaining the students' perception about limited job availability for BA university graduates and their preference for career development in this sectors. Also, low salaries existing in health, social work and education sectors (mostly public owned ranking among the worst performers in terms of salaries with low growth prospects on both short and long term) as result of economic and social climate seems to demotivate BA students' career choices in these sectors. Both extrinsic factors related to the earning opportunities (Gokuladas, 2010; Beyon et al, 1998) and intrinsic factors related to professional challenges incurred (Feton S. et al, 1994), job content and career advancement opportunities (Aycan et Fikret-Pasa, 2003, Gokuladas 2010) are underpinning BA students' option for a career in retail or wholesale trading. Students' option for a career in public administration is mainly the result of extrinsic factors related to stability and job security (Gokuladas, 2010, Aycan et Fikret-Pasa, 2003).

If students' preference for certain economic sectors and the university degrees and qualifications provided by BUES are considered together, the survey reveals BA students' are opting for sectors where they consider they can exploit best their university degrees. Results for Q7 and Q8 confirm earlier findings of Kopanidis and Shaw (2014), Greenbank (2011), $\mathrm{Ng}$ et al (2008) that the university students' option for particular educational paths or field of study is linked to their career objectives and opportunities, indicating that Romanian BA students' career choice is a rational model: option for a specific university and field of study is a question of future employability and of the contribution it may add to help students to get access to careers in industries of which development is favored by the economic climate (extrinsic factors). Career choice is a very pragmatic process: BA students have chosen the university and their field of specialization which are best satisfying their career objectives, ensuring, thus, access to professions and jobs they are considering as being suitable and most satisfactory for them (in particular access to jobs in sectors in which brand employer, high earnings or security are perceived as being guaranteed). Consequently, BA students' preference for a particular field of university education is an early predictor for future career paths.

Results obtained for Q7 and Q8 indicate that the interpersonal factors related family and colleagues are important factors influencing BA students' perception about economic 
sectors and professions and consequently their further career choice. The structure of the respondents $(96.58 \%$ of the respondents are under 25 years, $78.63 \%$ enrolled in undergraduate programs and $80.54 \%$ with no employment or less than 1 year employment contract) is explaining the relative dominance of extrinsic factors in their initial career choice defined in terms of industry and professions.

Results obtained also indicate that students' choice is based on their perceptions about career opportunities in various sectors. To this end, it is important to understand how their perceptions are created. If results for Q7 are considered together with respondents profile, it seems that students' perceptions about career options depends on the information they acquired mostly from their families, colleagues and professors, as most important interpersonal factors for the respondents' career choice. If the respondents' employment status (the absence or less than 1 year under employment for $80.54 \%$ of the respondents) is added to previous considerations, it may explain why intrinsic factors have a residual importance for BA students: their perceptions are mostly based on information collected from external trusted sources (namely the family, professors and colleagues) and not on their direct and personal experience; in other words since they lack information collected through their personal employment experience, it is difficult to refer to the intrinsic factors as determinants of their career choice. This is an important aspect to be taken into consideration, since the limited perspective of family or professors across various professions, sectors or about evolution of economic climate may alter the students' perception about career paths and consequently the quality of their career choice.

The Q11 asked students to rank on 4 points Likert scale (1 - very important, 2 important, 3 - less important, 4 -most important) the importance of exposure to professions (various working experiences) for BA students' career choice. Based on mean scores obtained, internships and employment contracts are considered the most important factors influencing their career choice, while volunteering is less relevant for BA students (table 3).

Table 3. Working experiences influencing career choice

\begin{tabular}{|l|l|l|l|}
\hline & $\mathrm{N}$ & Mean & Std. Deviation \\
\hline Internships & 496 & 3,14 & 1,007 \\
Volunteering & 496 & 2,08 &, 971 \\
Entrepreneurship & 496 & 2,11 &, 971 \\
Paid employment contracts & 496 & 2,67 & 1,149 \\
Valid N (listwise) & 496 & & \\
\hline
\end{tabular}

Results for Q11 indicate internships as the most important type of working experience influencing BA students' career choice: $48.59 \%$ of the respondent ranked it as the most important and $27.02 \%$ of the respondents ranked it as important. Internships ensure conditions for students to gain practical experience through experiential learning (Ching et al, 2013), to put into practice the theory they learned to school, contributing (directly and indirectly to the sustainability of the learning process and support students in grounding their theoretical knowledge into the reality; thus internships are effective tools helping student to make better career choices (Brooks et al, 1995). Both internships and employment contracts are supporting students to develop job related skills which are not 
traditionally delivered within formal education (Garavan T., 2001). Paid employment contracts are considered a type of working experience significantly influencing career choice for BA students $31.65 \%$ of the respondent ranked it as the most important and $27.22 \%$ of the respondents ranked it as important). Paid employment was ranked the second since, as compared to internships, since it has the disadvantage of limited flexibility of working hours which may have detrimental effects related to time allocated for education. The least relevant working experience is volunteering. If extrinsic factors and preference for dynamic and rewarding (in terms of salaries and growth perspectives) economic sectors (Q7 and Q8) are taken into consideration, it seems that BA students prefer direct early exposure (direct working experiences) to economic sectors, professions and jobs which they could accede to according to their university degree and specialization; even if volunteering is providing some working experience, it is rather associated with social works and charity, which explains why it is the least preferred by BA students.

The results for Q11 confirm BA students' rational career choice model: early exposure to professions and industries is important for better understanding the content of specific jobs and for their employability objectives. BA students are considering that early exposure to professions (interpersonal factor) could support them to make better career choice; to make it effective, exposure to profession has to ensure students' direct contact to job content and responsibilities (intrinsic factors). The pragmatism of BA students' career choice is obvious: early exposure to professions for career choice is not just declarative, students are making use of various opportunities to acquire this experience (68.15\% of the respondents have various working experiences).

\section{Conclusions and practical recommendations}

The survey on Romanian BA students confirms that enrolment in university education and preference for a specific field of study are employability driven and an early predictor of their future career pathway: university education is facilitating access to better paid jobs (UNICEF, 2014). The option for a specific field of studies is the decisive for students' career objectives since it is being considered a prerequisite for students' access to attractive jobs in attractive sectors. BA students' career choices seem to be extrinsic factors driven: they prefer either economic sectors with significant growth potential offering well paid jobs and good employer brands (financial activities, banking and insurance), either sectors perceived to guarantee job stability and security (as it is the case for public administration). Also, interpersonal factors, in particular family and relatives and early exposure to professions, are significantly influencing the career choices for BA students. Family and relatives are important contributors to BA students' perceptions about career opportunities with impact on both their initial career choice and learning pathways. The extrinsic factors and parental influence seem to be important at initial phases of career choice and design. It seems that BA students, following their initial option for a particular learning pathway during university education, they also need to understand the job content and responsibilities, through direct exposure to profession, before making further career choices,. To this end, most students are attempting to ensure and diversify their working experience during university education; all types of 
working experiences are considered by BA students since they are helping them to develop job related skills and to make better professional choices. Personal exposure to sectors and jobs as critical through internships and other working experiences creates conditions for students to introduce intrinsic factors (related to job content) in their career choice model. BA students are considering direct personal exposure to sectors and jobs and intrinsic factors as critical for their career choice in latter stages.

For BA students, interpersonal factors are relevant for their initial career choice, in particular related to their university education and profession. University education and extrinsic factors are mostly linked with students' option for a particular industry. Direct exposure to professions through personal working experience (internships and volunteering included) is both equipping students with employability skills and is revealing to the students the intrinsic factors (related to specific jobs content) to be considered for their career pathway development. Based on these findings, BUES management is considering both to develop quality guiding and counselling services (coherent with high school guiding and counselling) and to diversify the working experiences opportunities for students (in particular internships opportunities) so that to help BA students to make better career choices.

\section{Acknowledgement}

This paper findings and analysis are based on a survey conducted on undergraduate and master students of the Bucharest University of Economic Studies, during the academic year 2014-2015, within the project "Human Resources Internships for Students - PREUS", contract POSDRU/161/2.1/G/137915, co-funded from European Social Fund under 2007-2013 Sectoral Operational Program for Human Resources Development.

\section{References}

Aycan, Z. and Fikret-Pasa, S. (2003), "Career choices, job selection criteria and leadership preferences in a transitional nation: the case of Turkey", Journal of Career Development, Vol. 30 No. 2.

Bai, L. (1998), "Monetary reward versus the national ideological agenda: career choice among Chinese university students", Journal of Moral Education, Vol. 27 No. 4

Bennett, R. (2004), "Students' motives for enrolling on business degrees in a post-1992 university", International Journal of Educational Management, Vol. 18 No. 1.

Beyon, J., Toohey, K. and Kishor, N. (1998), "Do visible minority students of Chinese and South Asian ancestry want teaching as a career? Perceptions of some secondary school students in Vancouver, BC", Canadian Ethnic Studies, Vol. 30 No. 2.

Brooks, L.; Cornelius, A.; Greenfield, E.; Joseph, R.; The relation of career related work or internship experience to the career development of college seniors, Journal of Vocational Behaviour, 1995, 46

Carlson, A. and Wertheimer, A. (1992), "Occupational inheritance and business orientation in pharmacy", Journal of Social and Administrative Pharmacy, Vol. 9

Carpenter, P. and Foster, B. (1977), "The career decisions of student teachers", Educational Research and Perspectives, Vol. 4 No. 1.

Ching-Sung, L.; Chen-Wei C. Intention to "Leave" or "Stay" - The Role of Internship Organization in the Improvement of Hospitality Students' Industry Employment Intentions, Asia Pacific Journal of Tourism Research, 2013, 18:7 
Da Silva Anana, E.,Nique, W.M. (2010), "Personal values in relation to graduate career choices", International Journal of Public Sector Management, Vol. 23 No. 2.

Edvardsson Stiwne, E. (2005), "The first year as engineering student - the experiences of four cohorts of engineering students in Applied Physics and Electrical Engineering in Linkoping University", paper presented at the 1st Annual CDIO Conference Queen's University, Kingston, Ontario.

Felton, S., Buhr, N., Northe, M., (1994), "Factors influencing the business students choice of a career in chartered accountancy", Issues in Accounting education, vol. 9, no. 1.

Garavan, T.; Murphy, C.; The cooperative education process and organizational socialization: a qualitative study of students perception of its effectiveness, Education+Training, $2001 \mathrm{vol} 43$,

Gleeson, D., Gough, G., Glover, D. and Johnson, M. (1993), "Pharmacists in training: professional development or professionalism at risk?”, The Pharmaceutical Journal, Vol. 251

Gokuladas, V.K., (2010), "Factors that influence first-career choice of undergraduate engineers in software services companies: A south Indian experience", Career Development International, Vol. 15 Issue 2

Goyettet, K.A. and Mullen, A.L. (2006), "Who studies the arts and sciences? Social background and the choice and consequences of undergraduate field of study", Journal of Higher Education, Vol. 77 No. 3.

Greenbank, P. (2011), "Improving the process of career decision making: an action research approach", Education+Training, Vol. 53 No. 4.

Julien, H.E. (1999), "Barriers to adolescents' information seeking for career decision making",

Journal of the American Society for Information Science, Vol. 50 No. 1

Kahle, L.R. and Kennedy, P. (1989), "Using the list of values (LOV) to understand consumers", Journal of Consumer Marketing, Vol. 6 No. 3.

Kopanidis, Z.K., Shaw, M.J. (2014), “Courses and careers: measuring how students' personal values matter", Education+Training, vol. 56, no. 5 .

McGraw, K., Popp, J.S., Dixon, B.L., Newton, D.J. (2012) "Factors Influencing Job Choice among Agricultural Economics Professionals", Journal of Agricultural and Applied Economics, vol. 44, no. 2.

Ng, E.S.W., Burke, R.J. and Fiksenbaum, L. (2008), "Career choice in management: findings from US MBA students", Career Development International, Vol. 13 No. 4.

Rascati, K. (1989), "Career choice, plans, and commitment of pharmacy students", American Journal of Pharmaceutical Education, Vol. 53.

Singh, P., Bhandarker, A., Rai, S. and Jain, A.K. (2011), "Relationship between values and workplace: an exploratory analysis", Facilities, Vol. 29 Nos 11/12.

UNICEF (2014), "The cost of non-investing in education in Romania", Final Report

Vigoda-Gadot, E., Grimland, S. (2008), "Values and career choice at the beginning of the MBA educational process", Career Development International, Vol. 13 No. 4.

Wheeler, K.G., (1983), "Perceptions of Labor Market Variables by College Students in Business, Education and Psychology", Journal of Vocational Behavior, Vol. 22.

Willis, S.C.; Shann, P.; Hassell, K.,(2009),"Pharmacy career deciding: making choice a "good fit”", Journal of Health Organization and Management, Vol. 23 Issue 1 